\title{
Two Novel Genomospecies in the Agrobacterium tumefaciens Species Complex Associated with Rose Crown Gall
}

\author{
Hamzeh Mafakheri, ${ }^{1}$ S. Mohsen Taghavi, ${ }^{1}$ Joanna Puławska, ${ }^{2}$ Philippe de Lajudie, ${ }^{3}$ Florent Lassalle, ${ }^{4}$ \\ and Ebrahim Osdaghi ${ }^{1, \dagger}$ \\ ${ }^{1}$ Department of Plant Protection, College of Agriculture, Shiraz University, Shiraz 71441-65186, Iran \\ ${ }^{2}$ Research Institute of Horticulture, 96-100 Skierniewice, Poland \\ ${ }^{3}$ IRD (Institut de recherche pour le développement), Campus de Baillarguet TA A-82/J, Laboratoire des Symbioses Tropicales et Méditerranéennes, \\ 34398 Montpellier Cédex 5, France \\ ${ }_{4}^{4}$ Department of Infectious Disease Epidemiology, St. Mary's Hospital Campus, Imperial College London, London W2 1NY, United Kingdom \\ Accepted for publication 10 July 2019.
}

\begin{abstract}
In this study, we explored the pathogenicity and phylogenetic position of Agrobacterium spp. strains isolated from crown gall tissues on annual, perennial, and ornamental plants in Iran. Of the 43 strains studied, 10 strains were identified as Allorhizobium vitis (formerly Agrobacterium vitis) using the species-specific primer pair PGF/PGR. Thirty-three remaining strains were studied using multilocus sequence analysis of four housekeeping genes (i.e., $a t p D, \operatorname{gyr} B$, $r e c A$, and $r p o B$ ), from which seven strains were identified as $A$. larrymoorei and one strain was identified as $A$. rubi (Rer); the remaining 25 strains were scattered within the A. tumefaciens species complex. Two strains were identified as genomospecies 1 (G1), seven strains were identified as A. radiobacter

from apple were clustered in three atypical clades within the A. tumefaciens species complex. All but eight strains (i.e., Nec10, Ph38, Ph49, fic9, Fic72, R13, OT33, and Ap1) were pathogenic on tomato and sunflower seedlings in greenhouse conditions, whereas all but three strains (i.e., fic9, Fic72, and OT33) showed tumorigenicity on carrot root discs. The phylogenetic analysis and nucleotide diversity statistics suggested the existence of two novel genomospecies within the A. tumefaciens species complex, which we named "G19" and "G20." Hence, we propose the strains Rew, Rnw, and Rnr as the members of "G19" and the strains R13 and OT33 as the members of G20, whereas the phylogenetic status of the atypical strain Ap1 remains undetermined.
\end{abstract} (G4), seven strains were identified as A. deltaense (G7), two strains were identified as A. nepotum (G14), and one strain was identified as "A. viscosum" (G15). The strains Rnr, Rnw, and Rew as well as the two strains OT33 and R13 all isolated from rose and the strain Ap1 isolated
Keywords: agrobacteria, etiology, MLSA, Rhizobiaceae, Rhizobium radiobacter, tumorigenesis
Agrobacteria are members of the bacterial family Rhizobiaceae that dwell in soil and cause crown gall and hairy root diseases on a broad range of plant species (Bosmans et al. 2015; Pulawska 2010). Members of Agrobacterium spp. are responsible for economic losses in nurseries of economically important fruit trees and ornamental plants, including almond (Prunus dulcis), grapevine (Vitis vinifera), peach (Prunus persica), plum (Prunus domestica), rose (Rosa spp.), walnut (Juglans spp.), and weeping fig (Ficus benjamina) (Campillo et al. 2012). The taxonomy of Agrobacterium spp. has been constantly changing over the past century, and it has also been debated (Puławska et al. 2016). This was mostly because of the fact that taxonomy of agrobacteria was based on the symptomatology of host plants. Originally, the strains causing tumor and hairy root were classified as A. tumefaciens and A. rhizogenes, respectively, whereas those that were not pathogenic were assigned into A. radiobacter (Tzfira and Citovsky 2008). Pathogenicity of agrobacteria is induced by a set of virulence genes (vir genes) located on a tumor-inducing plasmid (tumour inducing plasmid). Accordingly, this classification is no longer valid, because it has been noted that the Ti plasmid is conjugative and

${ }^{\dagger}$ Corresponding author: E. Osdaghi; eosdaghi@ shirazu.ac.ir

Funding: Financial support for this study was provided by Shiraz University.

*The $\boldsymbol{e}$-Xtra logo stands for "electronic extra" and indicates that six supplementary figures and two supplementary tables are published online.

The author(s) declare no conflict of interest.

(C) 2019 The American Phytopathological Society can be transferred into nonpathogenic agrobacteria, converting them to becoming pathogenic (Puławska 2016).

In the early 1970s, physiological and biochemical analyses revealed that agrobacteria, regardless of their virulence features, could be divided into three biovars (Keane et al. 1970; Kerr and Panagopoulos 1977; Kersters et al. 1973; White 1972). Additional studies using chemotaxonomy (Jarvis et al. 1996; Tighe et al. 2000), DNA-DNA hybridization (De Ley et al. 1973), and 16S ribosomal DNA (rDNA) sequence analyses (Bouzar and Jones 2001; Puławska et al. 2000; Sawada et al. 1993) confirmed the new biovar-based classification of Agrobacterium spp. (Puławska 2016). Nevertheless, each of the three Agrobacterium biovars could include tumorigenic, rhizogenic, or nonpathogenic strains, which were determined by the plasmid carried by a particular strain (Keane et al. 1970; Kersters et al. 1973; White 1972). Later, Holmes and Roberts (1981) raised biovars 1 and 2 to the species level, corresponding to A. tumefaciens and A. rhizogenes, respectively, where epithets "tumefaciens" and "rhizogenes" did not imply pathogenic properties of the strains. Ophel and Kerr (1990) have also described Allorhizobium vitis corresponding to biovar 3 .

By the beginning of the genomic era, phylogenetic analyses of $16 \mathrm{~S}$ rDNA sequences suggested transferring all of the Agrobacterium spp. members into the Rhizobium spp. (Young et al. 2001). However, Farrand et al. (2003) supported the term "Agrobacterium spp." as a proper name for the phytopathogenic members of the family Rhizobiaceae. Indeed, molecular-phylogenetic investigations revealed $A$. rhizogenes (formerly A. tumefaciens biovar 2) as a true member of Rhizobium spp., whereas other pathogenic taxa were considered Agrobacterium spp. During the past decade, the availability of complete genome sequencing 
facilities led to a revised phylogeny of the family Rhizobiaceae. Therefore, several strains were classified as new species: that is, A. arsenijevicii (Kuzmanović et al. 2015), A. bohemicum (Zahradník et al. 2018), A. deltaense (Yan et al. 2017a), A. larrymoorei, A. nepotum, A. radiobacter, A. rosae (Kuzmanović et al. 2018a), A. rubi, A. salinitolerans (Yan et al. 2017b), A. skierniewicense, Allorhizobium vitis (synonym A. vitis), Rhizobium rhizogenes (Mousavi et al. 2015; Ormeño-Orrillo et al. 2015), and Rhizobium tumorigenes (Kuzmanović et al. 2018b).

Nevertheless, taxonomy of "A. tumefaciens species complex" (biovar 1) is undergoing substantial reconsiderations because of not only the inhomogeneous nature of the species but also, the isolation of novel strains from various environments. So far, 11 genomic species "genomospecies" (G; i.e., G1 to G9, G13, and G14) were defined within the A. tumefaciens species complex based on DNADNA hybridization and amplified fragment length polymorphism (AFLP) analyses (Mougel et al. 2002; Portier et al. 2006; Puławska and Kałużna 2011). It has also been noted that the results of multilocus sequence analysis (MLSA) based on the sequences of four housekeeping genes (i.e., $a t p D, \operatorname{gyr} B, \operatorname{rec} A$, and $r p o B$ ) are in congruence with those of DNA-DNA hybridization and AFLP results (Costechareyre et al. 2010; Puławska and Kałużna 2011). Five of 11 genomospecies have valid species-level binominal names: that is, A. pusense (G2) (Panday et al. 2011), A. radiobacter (G4) (Costechareyre et al. 2010; Lindstrom and Young 2011), A. nepotum (G14) (Puławska et al. 2012), "A. fabrum" (G8) (Lassalle et al.2011), A. salinitolerans (G9) (Yan et al. 2017b), and A. deltaense (G7) (Yan et al. 2017a). Six genomospecies remain to receive taxonomically valid species names. In the case of $A$. arsenijevicii, which is taxonomically a member of $A$. tumefaciens species complex, the binominal name has directly been assigned to the strains without previous genomospecies delineation (Kuzmanović et al. 2015).

Crown gall pathogen-infecting grapevine trees were first reported in Iran in 1966 (Amani 1966). Currently, several economically important agricultural plants, including grapevine, rose, stone fruits, and sugar beet, are reported to be infected with crown gall pathogens in the country (Mafakheri et al. 2017). Although a number of investigations were conducted to decipher the etiology and genetic diversity of agrobacteria in Iran (Rouhrazi and Rahimian 2012), much of the molecular, phylogenetic, and host range information on the plant-pathogenic members of A. tumefaciens remains unexplored. During the past decade, several crown gall outbreaks were observed in annual crop fields and perennial plant nurseries in Iran. Preliminary investigations on sugar beet strains isolated in southern Iran using the sequences of $g y r B$ and $r e c A$ genes revealed that the causal agent belong to genetically diverse groups representing members of the A. tumefaciens species complex (Mafakheri et al. 2017).

The purpose of this study was to elucidate the taxonomic position of crown gall-inducing agrobacteria in Iran using molecular phylogenetic approaches. We used pathogenicity assays, specific PCRs, and MLSA to characterize the strains isolated from various plant species from 2009 to 2018 . Our results revealed that, aside from the previously described species/genomospecies of A. tumefaciens, two novel genomospecies and one atypical strain could be defined among the A. tumefaciens complex species that were isolated from rose and apple plants in Iran.

\section{MATERIALS AND METHODS}

Samplings and bacterial isolation. The bacterial strains used in this study were isolated from gall tissues of different annual and perennial plants during field surveys and inspections in Iran from 2009 to 2018. This study follows a countrywide quarantine inspection program for the monitoring of bacterial diseases of forage crops (Ansari et al. 2019; Yaripour et al. 2018), vegetables (Osdaghi et al. 2018a, b; Sedighian et al. 2014), and fruit trees (Zarei et al. 2019) in Iran. Surveys were conducted throughout Fars,
Isfahan, Kohgiluyeh-Boyer-Ahmad, Kurdistan, Mazandaran, and Tehran provinces in southern, central, northern, and western Iran. Symptomatic plants possessing gall tissues on the root, crown, or aboveground parts of the plants were sampled. Plant tissues were washed under running tap water, surface sterilized by dipping into $0.5 \%$ sodium hypochlorite for $2 \mathrm{~min}$, and rinsed three times in sterile distilled water (SDW). Small portions of the gall tissues were aseptically cut and macerated in a few drops of SDW using a sterile mortar and a pestle. A loopful of the resulting suspension was streaked simultaneously onto each of the nutrient agar (NA) and 1A media to broaden the range of isolated bacterial strains (Campillo et al. 2012). Although the medium 1A was specifically designed for the isolation of $A$. tumefaciens species complex (biovar 1), the NA medium allowed us to retrieve a broader range of bacterial strains (Campillo et al. 2012). The plates were incubated at $27^{\circ} \mathrm{C}$ for 3 to 4 days, and the resulting colonies were purified by multiple streaking onto fresh NA medium. The bacterial strains (Table 1) were resuspended in SDW and stored at $4{ }^{\circ} \mathrm{C}$ for further use or maintained in $15 \%$ glycerol at $-70^{\circ} \mathrm{C}$ for long-term storage.

Pathogenicity tests. All of the strains isolated in this study were evaluated for their pathogenicity on tomato (Solanum lycopersicum 'Sunseed 6189') and sunflower (Helianthus annuus 'Armavirski') plants in greenhouse conditions as well as carrot (Daucus carota 'Nantesforto') root discs in petri dishes. For the in vitro pathogenicity test, fresh carrot roots were surface sterilized with a $70 \%$ ethanol solution, rinsed three times in SDW, and cut into 5-mm-diameter discs. A bacterial suspension consisting of $1 \times 10^{8} \mathrm{CFU} / \mathrm{ml}$ was prepared from a 48 -h-old culture grown on NA medium. The discs (five discs per strain) were placed in sterile petri dishes on wet sterile filter paper and drop inoculated using $20 \mu \mathrm{l}$ of the freshly prepared bacterial suspension. Petri dishes were incubated in a dark incubator at $28^{\circ} \mathrm{C}$ up to 35 days postinoculation (dpi). Furthermore, plants were grown in 20-cm-diameter pots (three plants per pot), and they were maintained in a greenhouse under ambient conditions $\left(25\right.$ to $28^{\circ} \mathrm{C}, 14$ $\mathrm{h}$, natural light) as described previously (Osdaghi et al. 2015). Six plants per strain were inoculated, and the inoculation was conducted on the plants when they had at least three expanded true leaves (10 to 15 days old depending on the plant species). Inoculation was performed using the needle prick method as described by Moore et al. (2001). The inoculated plants were maintained in the greenhouse conditions, and the symptom development was monitored periodically up to $60 \mathrm{dpi}$. A reference strain of $A$. radiobacter (formerly A. tumefaciens) ICMP 5856 was used as a positive control. Negative control plants were treated in the same manner, whereas SDW was used instead of bacterial suspension. All experiments were repeated twice. Koch's postulates were accomplished by reisolating the inoculated strains on NA medium from plants showing symptoms. Confirmation of the reisolated bacteria was made using VirD2A/ VirD2C PCR primers (Haas et al. 1995). A given strain was considered pathogenic when it induced crown gall symptoms on at least two-thirds of the inoculated plants/discs in each experiment.

Specific PCRs. All bacterial strains were tested using the specific primer pairs. We used the specific primer pairs F8360/ F8361 (Shams et al. 2013), virD2A/virD2C (Haas et al. 1995), VCF/ VCR (Sawada et al. 1995), and tms2F1/tms2R2 (Puławska and Sobiczewski 2005) as well as the Allorhizobium vitis-specific primer pair PGF/PGR (Szegedi and Bottka 2002) for screening all bacterial strains. The sequences of the primers and their respective annealing temperatures are described. Reference/type strains of A. radiobacter (ICMP 5856 $\left.{ }^{\mathrm{T}}\right)$, A. tumefaciens genomospecies G8 (=

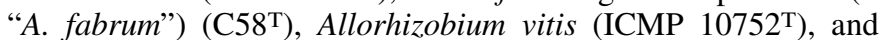
$R$. rhizogenes (K599) were used as controls. DNA preparation was carried out as described previously (Osdaghi et al. 2016). For PCR reactions, Universal PCR Kit Ampliqon Taq DNA Polymerase Master Mix Red (Ampliqon A/S) was used according to the manufacturer's recommendations. For each strain, a $25-\mu \mathrm{l} \mathrm{PCR,}$ including $50 \mathrm{ng}$ of total DNA and $1 \mu \mathrm{l}$ of each primer $\left(10 \mathrm{pmol} \mu \mathrm{l}^{-1}\right)$, was used. 
Phylogenetic analysis and genetic diversity. To obtain precise and reliable data on the phylogenetic position of the bacterial strains isolated in this study, they were subjected to MLSA using the sequences of four housekeeping genes (i.e., atpD, gyrB, $\operatorname{rec} A$, and $r p o B$ ) as recommended in the literature (Costechareyre et al. 2010; Kuzmanović et al. 2018a; Puławska and Kałużna 2011). These loci were shown to provide robust phylogeny and are sufficient to reliably resolve evolutionary relationships among the rhizobia and agrobacteria. The PCR parameters were the same as described above, whereas the sequences and annealing temperature of the primer pairs are shown in Supplementary Table S1. PCR products were sent to Bioneer Corporation (http://www.Bioneer.com) to be sequenced via Sanger sequencing technology. BLAST (https://blast.ncbi.nlm.nih. gov/) searches on the NCBI GenBank database using the resulting DNA sequences revealed that the individual strains isolated in Iran were showing sequence similarity of 91 to $100 \%$ to the type/standard strains of different species/genomospecies within agrobacteria. Hence, the respective sequences of these four genes in a collection of 38 worldwide Agrobacterium spp. strains were retrieved from the GenBank databases and included in the phylogenetic analyses (Costechareyre et al. 2010; Kuzmanović et al. 2018a; Puławska and Kałużna 2011). Sequences were concatenated following the alphabetic order of the genes, ending in a sequence of 2,027 base pairs: nucleotides 1 to 436 for $a t p D, 437$ to 915 for gyrB, 916 to 1,279 for $r e c A$, and 1,280 to 2,027 for rpoB. Phylogenetic trees were constructed using the maximum likelihood method with MEGA 6.06 software (Tamura et al. 2013). The model of evolution for maximum likelihood analysis was determined using the Modeltest tab in MEGA 6.06. Mesorhizobium tianshanense (USDA3592) was used to root the phylogenetic trees, and they were constructed with bootstrapping (1,000 replications).

Nucleotide diversity, the number of haplotypes, and the minimum number of recombination events were determined using DnaSP 5.10 software (Librado and Rozas 2009). Multiple methods were used to detect recombination among the strains/genomospecies. Detection of potential recombinant sequences and identification of likely parental sequences were carried out using a set of seven nonparametric detection methods (i.e., Recombination Detection Program [RDP], Geneconv, MaxChi, Chimaera, BootScan, SiScan, and 3Seq) implemented in RDP version 4.80 (Martin et al. 2015). The analysis was performed with default settings for the different detection methods, and the Bonferroni-corrected $P$-value cutoff was set at 0.05 . Recombination events were accepted when they were identified by at least four of seven detection methods (Martin et al. 2015). NeighborNet networks were constructed for the individual gene sequences as well as the concatenated dataset, and the pairwise homoplasy index (PHI) was calculated using SplitsTree version 4.14.4 (Huson and Bryant 2006). To visualize the relationships between the DNA sequences of the strains, haplotype networks were inferred for individual housekeeping genes using the TCS algorithm (Clement et al. 2002) implemented in PopART version 1.7 software (Leigh and Bryant 2015). The host plant of the strains was delineated into the haplotype network of each of the housekeeping genes.

TABLE 1. Bacterial strains used in this study, their place and date of isolation, and the results of specific PCRs and pathogenicity tests

\begin{tabular}{|c|c|c|c|c|c|c|c|c|c|c|c|c|c|}
\hline \multirow[b]{2}{*}{ Strain } & \multicolumn{2}{|c|}{ Host of isolation } & \multirow{2}{*}{\multicolumn{2}{|c|}{ Origin }} & \multirow[b]{2}{*}{ Date } & \multirow[b]{2}{*}{ Species name } & \multirow[b]{2}{*}{ Genomospecies } & \multirow[b]{2}{*}{ Pathogenicity } & \multicolumn{5}{|c|}{ Specific PCR tests } \\
\hline & $\begin{array}{l}\text { Common } \\
\text { name }\end{array}$ & Scientific name & & County & & & & & $\begin{array}{l}\text { VCF } \\
\text { VCR }\end{array}$ & $\begin{array}{l}\text { tms2F1 } \\
\text { tms2R2 }\end{array}$ & virD2AvirD2C & $\begin{array}{l}\text { F8360 } \\
\text { F8361 }\end{array}$ & $\begin{array}{l}\text { PGF } \\
\text { PGR }\end{array}$ \\
\hline Nec10 & Nectarine & $\begin{array}{l}\text { Prunus persica } \\
\quad \text { var. nucipersica }\end{array}$ & Mazandaran & Kelardasht & 2015 & A. radiobacter & G4 & $t^{\mathrm{a}}$ & + & + & + & + & - \\
\hline $\mathrm{Ph} 38$ & Peach & Prunus persica & Mazandaran & Kelardasht & 2015 & A. radiobacter & G4 & $t^{\mathrm{a}}$ & + & + & + & + & - \\
\hline $\mathrm{Ph} 41$ & Peach & Prunus persica & Mazandaran & Kelardasht & 2015 & A. radiobacter & G4 & + & + & + & + & + & - \\
\hline Ap42 & Apple & Malus pumila & Mazandaran & Kelardasht & 2015 & A. radiobacter & G4 & + & + & + & + & + & - \\
\hline Ph49 & Peach & Prunus persica & Mazandaran & Kelardasht & 2015 & A. radiobacter & G4 & $t^{\mathrm{a}}$ & + & + & + & + & - \\
\hline $\mathrm{Ph} 20$ & Peach & Prunus persica & Mazandaran & Kelardasht & 2015 & A. radiobacter & G4 & + & + & + & + & + & - \\
\hline Ph5 & Peach & Prunus persica & Mazandaran & Kelardasht & 2015 & A. radiobacter & G4 & + & + & + & + & + & - \\
\hline Rnr & Rose & Rosa spp. & Isfahan & Najafabad & 2016 & $N A^{b}$ & G19 & + & + & + & + & + & - \\
\hline Rnw & Rose & Rosa spp. & Isfahan & Najafabad & 2016 & NA & G19 & + & + & + & + & + & - \\
\hline Rew & Rose & Rosa spp. & Isfahan & Isfahan & 2016 & NA & G19 & + & + & + & + & + & - \\
\hline Ro16 & Rose & Rosa spp. & $\begin{array}{l}\text { Kohgiluyeh- } \\
\text { Boyer-Ahmad }\end{array}$ & Yasuj & 2009 & A. deltaense & G7 & + & + & + & + & + & - \\
\hline Ro17 & Rose & Rosa spp. & $\begin{array}{l}\text { Kohgiluyeh- } \\
\text { Boyer-Ahmad }\end{array}$ & Yasuj & 2009 & A. deltaense & G7 & + & + & + & + & + & - \\
\hline Ro18 & Rose & Rosa spp. & $\begin{array}{l}\text { Kohgiluyeh- } \\
\text { Boyer-Ahmad }\end{array}$ & Yasuj & 2009 & A. deltaense & G7 & + & + & + & + & + & - \\
\hline Ro19 & Rose & Rosa spp. & $\begin{array}{l}\text { Kohgiluyeh- } \\
\text { Boyer-Ahmad }\end{array}$ & Yasuj & 2009 & A. deltaense & G7 & + & + & + & + & + & - \\
\hline SB1 & Sugar beet & Beta vulgaris & Fars & Eghlid & 2013 & A. deltaense & G7 & + & + & + & + & + & - \\
\hline SB2 & Sugar beet & Beta vulgaris & Fars & Eghlid & 2013 & A. deltaense & G7 & + & + & + & + & + & - \\
\hline SB3 & Sugar beet & Beta vulgaris & Fars & Eghlid & 2013 & A. deltaense & G7 & + & + & + & + & + & - \\
\hline Fic9 & Weeping fig & Ficus benjamina & Fars & Shiraz & 2014 & A. nepotum & G14 & $t^{\mathrm{a}}$ & + & + & + & + & - \\
\hline Fic72 & Weeping fig & Ficus benjamina & Fars & Shiraz & 2014 & A. nepotum & G14 & $t^{\mathrm{a}}$ & + & + & + & + & - \\
\hline F957 & Weeping fig & Ficus benjamina & Fars & Shiraz & 2016 & A. larrymoorei & NA & + & + & + & + & + & - \\
\hline F5 & Weeping fig & Ficus benjamina & Fars & Shiraz & 2014 & A. larrymoorei & NA & + & + & + & + & + & - \\
\hline $\mathrm{Ft} 3$ & Weeping fig & Ficus benjamina & Tehran & Tehran & 2016 & A. larrymoorei & NA & + & - & + & - & + & - \\
\hline $\mathrm{Ft} 1$ & Weeping fig & Ficus benjamina & Tehran & Tehran & 2016 & A. larrymoorei & NA & + & _- & + & _- & + & - \\
\hline Fte22 & Weeping fig & Ficus benjamina & Tehran & Tehran & 2016 & A. larrymoorei & NA & + & + & + & + & + & - \\
\hline FT11 & Weeping fig & Ficus benjamina & Tehran & Tehran & 2017 & A. larrymoorei & NA & + & + & + & + & + & - \\
\hline FT15 & Weeping fig & Ficus benjamina & Tehran & Tehran & 2017 & A. larrymoorei & NA & + & + & + & + & + & - \\
\hline Rer & Rose & Rosa spp. & Isfahan & Isfahan & 2016 & A. rubi & NA & + & + & + & + & + & - \\
\hline R5 & Rose & Rosa spp. & Fars & Shiraz & 2018 & NA & G1 & + & + & + & + & + & - \\
\hline Ficamol & Weeping fig & Ficus benjamina & Mazandaran & Amol & 2018 & NA & G1 & + & + & + & + & + & - \\
\hline EsR & Rose & Rosa spp. & Isfahan & Isfahan & 2018 & A. viscosum & G15 & + & + & + & + & + & - \\
\hline R13 & Rose & Rosa spp. & Fars & Shiraz & 2018 & NA & G20 & $t^{\mathrm{a}}$ & + & + & - & + & _- \\
\hline OT33 & Rose & Rosa spp. & Fars & Zarqan & 2018 & NA & G20 & $t^{\mathrm{a}}$ & - & + & - & + & - \\
\hline Ap1 & Apple & Malus pumila & Shiraz & Shiraz & 2018 & NA & NA & $t^{\mathrm{a}}$ & + & + & + & + & - \\
\hline Viti20 & Grape & Vitis vinifera & Kurdistan & Dehgolan & 2016 & A. vitis & NA & + & + & + & + & + & + \\
\hline Viti22 & Grape & Vitis vinifera & Kurdistan & Dehgolan & 2016 & A. vitis & NA & + & + & + & + & + & + \\
\hline Ks1 & Grape & Vitis vinifera & Kurdistan & Serish abad & 2013 & A. vitis & NA & + & + & + & + & + & + \\
\hline Ks4 & Grape & Vitis vinifera & Kurdistan & Serish abad & 2013 & A. vitis & NA & + & + & + & + & + & + \\
\hline KG1 & Grape & Vitis vinifera & Kurdistan & Ghorveh & 2013 & A. vitis & NA & + & + & + & + & + & + \\
\hline KG2 & Grape & Vitis vinifera & Kurdistan & Ghorveh & 2013 & A. vitis & NA & + & - & + & + & + & + \\
\hline KG4 & Grape & Vitis vinifera & Kurdistan & Ghorveh & 2013 & A. vitis & NA & + & + & + & + & + & + \\
\hline Sep1 & Grape & Vitis vinifera & Fars & Sepidan & 2013 & A. vitis & NA & + & + & + & + & + & + \\
\hline Sep2 & Grape & Vitis vinifera & Fars & Sepidan & 2013 & A. vitis & NA & + & - & + & + & + & + \\
\hline Ss1 & Grape & Vitis vinifera & Kurdistan & Sisakht & 2013 & A. vitis & NA & + & + & + & + & + & + \\
\hline
\end{tabular}

a Nonpathogenic on tomato and sunflower but pathogenic on carrot discs.

b NA, not assigned. 
GenBank accession numbers and strain availability. The sequenced nucleotides were deposited into the GenBank database under the following accession numbers: atpD: MK881512 to MK881544; gyrB: KY913735 to KY913764, MG917084 to MG917085, and MK881545 to MK881550; recA: KY913765 to KY913790, MG917086 to MG917087, and MK881551 to MK881556; and rpoB: MK881557 to MK881589. Furthermore, a pure culture of the representative strains recovered in this study was deposited in the International Center for Microbial Resources-French Collection for Plant-associated Bacteria (CIRM-CFBP) culture collection (French Collection for Plant-Associated Bacteria) and assigned accession numbers as follows: Fte22 = CFBP 8620, Ph38 = CFBP 8621, SB2 = CFBP 8623, and Rew = CFBP 8624.

\section{RESULTS}

Disease incidence and pathogenicity tests. Crown gall symptoms were frequently detected on annual crops (i.e., sugar beet), fruit trees (i.e., apple, grapevine, peach, and nectarine), and ornamental plants (i.e., rose and weeping fig) throughout various geographical areas in Iran. The most severe symptoms were observed on weeping fig plants (Supplementary Fig. S1) and rose rootstocks in commercial nurseries in Fars, Isfahan, and Tehran provinces. Altogether, 43 agrobacterial strains were isolated from the symptomatic plants in Iran, among which 12 strains were isolated from rose, whereas 10 strains were isolated from both grapevine and weeping fig plants. Three strains were isolated from sugar beet, and two, one, and five strains were isolated from apple, nectarine, and peach trees, respectively (Table 1).

Crown gall symptoms appeared 15 dpi on inoculated plants in the greenhouse conditions. All of the strains isolated from grapevine and sugar beet were pathogenic on all of the three test plants, whereas the strain Nec10, which was isolated from nectarine, was tumorigenic only on carrot root discs. The strains isolated from apple, peach, rose, and weeping fig showed variable results. Although the strains Ap1 (isolated from apple), $\mathrm{Ph} 38, \mathrm{Ph} 49$ (isolated from peach), and R13 (isolated from rose) were tumorigenic only on carrot root discs, the remaining strains were pathogenic on all three test plants (Table 1). Although most of the strains were tumorigenic on carrot root discs within 15 dpi, the strains fic9, Fic72, and OT33 showed a delayed pathogenicity on carrot root discs and induced tumor tissues 30 to 40 dpi on only $20 \%$ of the inoculated discs. Hence, we did not consider the strains fic9, Fic72, and OT33 as pathogenic. These three strains might have narrow host range or attenuated virulence repertories on their $\mathrm{Ti}$ plasmid. Additional investigations (i.e., the complete $\mathrm{Ti}$ plasmid sequencing and a broader host range assay) are required to demonstrate pathogenicity status of these strains. Control plants remained asymptomatic, whereas the plants inoculated with the reference strain ICMP $5856^{\mathrm{T}}$ showed crown gall symptoms at $15 \mathrm{dpi}$.

Molecular-phylogenetic analyses. Specific PCRs. The primer pair F8360/F8361 directed the amplification of a 453-base pair DNA fragment in all 43 strains, confirming them as Agrobacterium spp. Furthermore, amplification of a 617-base pair DNA fragment in all 43 strains using the primer pair tms2F1/ tms2R2 revealed that all of the strains were carrying the Ti plasmid (data not shown). However, the species-specific primer pair PGF/ PGR directed the amplification of a 466-base pair DNA fragment in 10 of 43 strains (i.e., Viti20, Ks1, Ks4, KG1, KG2, KG4, Ss1, Viti2-2, Sep1, and Sep2), indicating that these strains belong to Allorhizobium vitis (Table 1). Because Allorhizobium vitis was considered as a homogenous species, the 10 strains identified as Allorhizobium vitis were excluded from the phylogenetic analysis. Whereas the VCF/VCR primer pair directed the amplification of a 730-base pair DNA fragment in all but the Fte3, Fte1, OT33, KG2, and Sep2 strains, the primer pair virD2A/virD2C amplified the expected 224-base pair DNA fragment in all but the Fte3, Fte1, R13, and OT33 strains. Positive results obtained from these latter primer pairs indicated that the respective strains carry the Ti plasmid.
Phylogenetic analysis. BLAST searches on the NCBI GenBank database using the partial sequences of four individual housekeeping genes (i.e., atpD, gyrB, recA, and $r p o B$ ) revealed that the strains isolated in Iran had a homology of 91 to $100 \%$ with the type/ reference strains of several genomospecies/species of A. tumefaciens species complex as well as A. rubi, A. larrymoorei, Rhizobium etli, and Neorhizobium spp. The phylogenetic tree constructed using the concatenated sequences of the four housekeeping genes confirmed the results obtained from BLAST analyses. Thirty-three Agrobacterium spp. strains isolated in Iran were clustered within 10 phylogroups, and the phylogenetic tree was strongly supported by high bootstrap values (Fig. 1). Eight strains were clustered of the A. tumefaciens species complex. The strain Rer isolated from rose in Isfahan in 2016 was clustered among the type strain of $A$. rubi (LMG 17935T), whereas seven strains (i.e., F5, F957, Ft1, FT11, FT15, Ft3, and Fte22) isolated from weeping fig in Tehran and Shiraz were clustered with A. larrymoorei-type strain (Fig. 1). For the 25 strains that were clustered within the $A$. tumefaciens species complex, 17 strains were scattered through the previously defined formal species: that is, A. radiobacter (G4: Ph38, Ap42, Ph49, $\mathrm{Ph} 41, \mathrm{Ph} 5, \mathrm{Ph} 20$, and Nec10), A. deltaense (G7: SB2, SB3, SB1, Ro16, Ro18, Ro17, and Ro19), A. nepotum (G14: fic9 and Fic72), and "A. viscosum" (G15: EsR). Because we did not have access to the gyrB gene sequence of the type strain of "A. viscosum" ATCC 31113T, a phylogenetic tree was constructed using the sequences of three housekeeping genes (i.e., atpD, $\operatorname{rec} A$, and $r p o B$ ), which confirmed the strain EsR as "A. viscosum" (Supplementary Fig. S2). BLAST search showed that the strain EsR had nucleotide identity values of $99.1,98.3$, and $98.4 \%$ with the type strain of "A. viscosum" ATCC $31113 \mathrm{~T}$ in the sequences of atpD, recA, and $r p o B$ genes, respectively. All of the strains identified as A. radiobacter were isolated from stone fruits or pome trees in Kelardasht County (northern Iran) in 2015, whereas A. deltaense strains were isolated from rose and sugar beet, and the two A. nepotum strains were isolated from weeping fig in Shiraz in 2014 (Fig. 1 and Table 1). The strains R5 and Ficamol, which were isolated in 2018 from rose and weeping fig, respectively, were clustered among the members of G1.

None of the strains isolated in Iran were clustered within G2, G3, G5, G6, G8, G9, or G13. However, three atypical clades, including six Iranian strains, were observed in the phylogenetic tree. The strain Ap1, which was isolated from apple in Shiraz in 2018, was clustered alongside the G1 strains but separated from the G1 strains by $45,3,2$, and 62 nucleotide differences in the sequences of the $a t p D, g y r B$, recA, and $r p o B$ genes, respectively (Supplementary Table S2). A BLAST search using the sequences of individual genes revealed that strain Ap1 had the highest nucleotide sequence homology to $R$. etli bv. phaseoli (CP007641.1; 93.81\%), A. tumefaciens (CP033027.1; 99.37\%), A. tumefaciens (KX646736.1; 99.44\%), and A. rubi (MF447450.1; 95.04\%) in the sequences of $a t p D$, gyrB, recA, and $r p o B$ genes, respectively. However, when the $R$. etli bv. phaseoli (CP007641.1) strain was added to the concatenated maximum likelihood phylogenetic tree, it was not clustered close to the strains Ap1 (data not shown). The strains Rnr, Rnw, and Rew isolated from rose in Isfahan in 2016 were clustered close to the nonpathogenic G3 strain CFBP 6623 isolated from antiseptic flask in France (Fig. 1). Interestingly, all of the Rnr, Rnw, and Rew strains belonged to the same multilocus haplotype with no diversity in the sequences of the four genes and differed from the CFBP 6623 strain by 21, 34, 36, and 31 nucleotides in the sequences of $a t p D$, gyrB, recA, and $r p o B$ genes, respectively. However, BLAST searches using the sequences of individual genes revealed that the Rnr, Rnw, and Rew strains had the highest sequence similarity to A. tumefaciens (CP032926.1; 97.03\%), "A. fabrum" (CP033034.1; 93.07\%), A. arsenijevicii (KP284163.1; 91.39\%), and A. rhizogenes (CP019701.2; 95.86\%) in the sequences of $a t p D, g y r B$, $r e c A$, and $r p o B$ genes, respectively. Furthermore, two strains (R13 and OT33) isolated from rose 
differed from the G7 (A. deltaense) strains by 10, 32, 9, and 16 nucleotides in the sequences of $a t p D, \operatorname{gyr} B, \operatorname{rec} A$, and $r p o B$ genes, respectively. BLAST results showed the highest sequence similarity to A. rhizogenes (CP019701.2; 98.62\%), A. rhizogenes (CP019701.2; 99.58\%), A. tumefaciens (AB738704.1; 98.89\%), and Agrobacterium spp. G7 Zutra3/1 (HG326905.1; 97.19\%) in the sequences of $a t p D, g y r B, r e c A$, and $r p o B$ genes, respectively. Similar results were observed in the phylogenetic trees constructed using the sequences of four individual genes (Supplementary Fig. S3).
Because the maximum likelihood phylogenies of the four individual genes showed conflicting topologies, phylogenetic networks were generated using the NeighborNet method for the concatenated dataset of sequences (Fig. 2) and for all of the individual genes (Supplementary Fig. S4). The phylogenetic network resulting from the NeighborNet analyses confirmed the divergence of Rnw, Rnr, and Rew strains from G3 in the concatenated dataset (Fig. 2). Furthermore, strains R13 and OT33 were clustered as a separate clade adjacent to A. deltaense strains. The atypical strain Ap1 was also clustered close to G1 while being

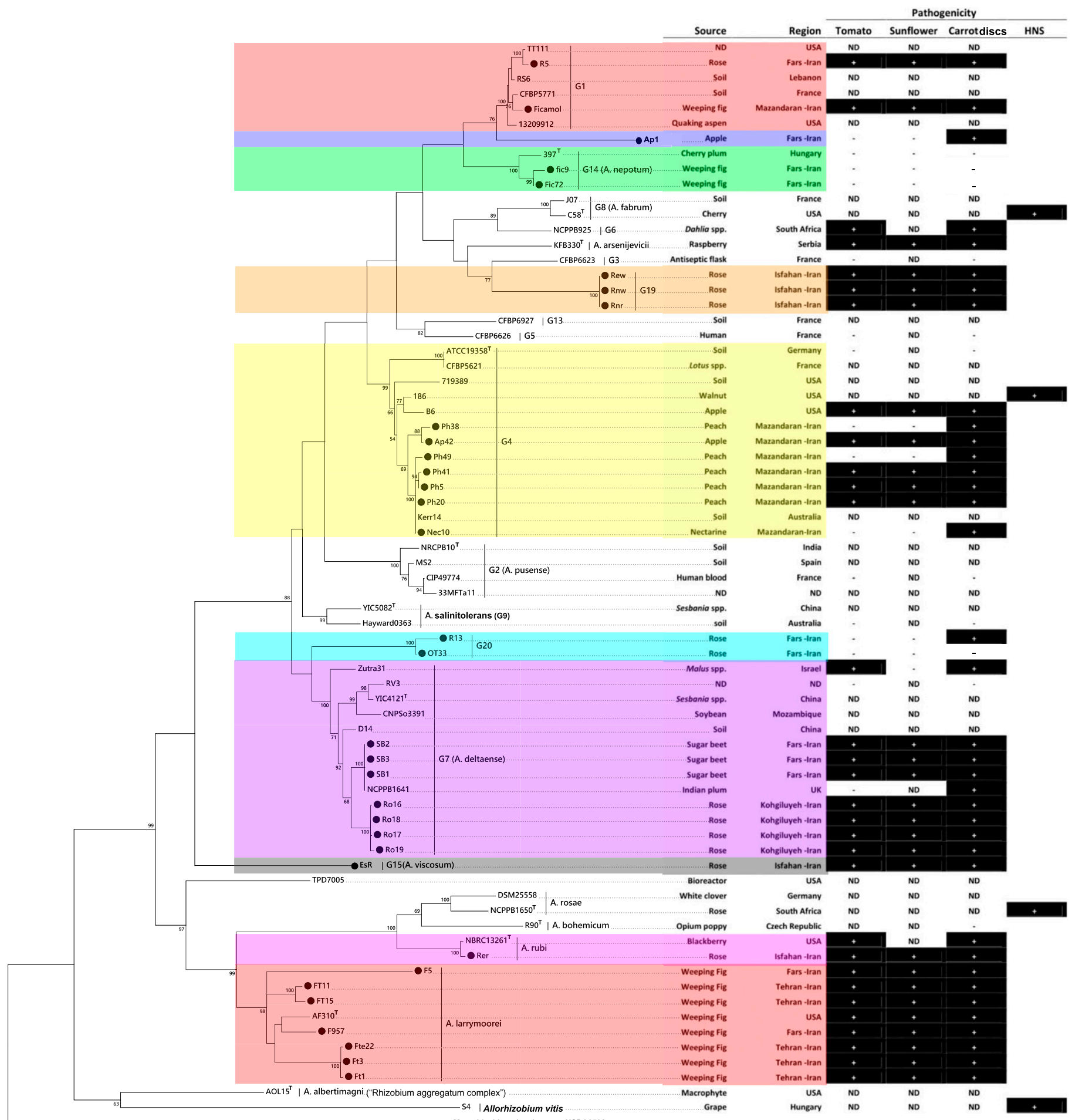

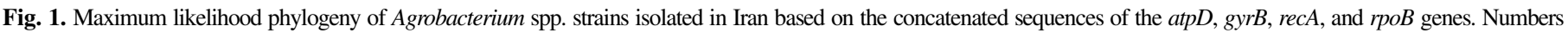

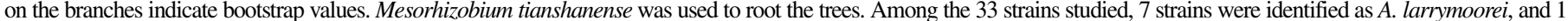
strain was identified as $A$. rubi, whereas the remaining 25 strains were scattered within the A. tumefaciens species complex. HNS, host not specified; ND, not determined. 
separated from the other species/genomospecies. Taken together, according to the results of the maximum likelihood tree and the NeighborNet network as well as the diversity parameters of the strains, the six strains that were clustered in three separate clades were considered as members of two novel genomospecies (G19 and G20) within the A. tumefaciens species complex, whereas the atypical strain Ap1 isolated from apple remains taxonomically undetermined. Hence, we propose G19 (i.e., Rew, Rnw, and Rnr) and G20 (i.e., R13 and OT33) as new members of the A. tumefaciens species complex. For strain Ap1, additional field surveys and molecular phylogenetic analyses are warranted to elucidate whether the atypical status of the strain is attributed to recombination within the strains. Although the G19 strains were pathogenic on all of the tested plant species (i.e., tomato, sunflower, and carrot root discs), the G20 and Ap1 strains were nonpathogenic on tomato and sunflower plants in the greenhouse conditions. Furthermore, the atypical strain Ap1 and the G20 strain R13 isolated from rose showed tumorigenicity on carrot root discs $14 \mathrm{dpi}$, whereas the other G20 strain (OT33) showed delayed tumorigenicity on a small fraction of the inoculated carrot root discs only $35 \mathrm{dpi}$; hence, the strain OT33 was considered as nonpathogenic.

Genetic diversity. Agrobacterial strains isolated in Iran carried different allelic forms and were placed in 28 multilocus haplotypes based on the concatenated sequences of four housekeeping genes. Several strains isolated in different geographic areas in Iran shared $100 \%$ sequence identity-in all four genes-with the strains isolated in other countries. For instance, two G4 (A. radiobacter) strains isolated from peach $(\mathrm{Ph} 20)$ and nectarine $(\mathrm{Nec} 10)$ shared the same multilocus haplotype with the strain Kerr14 isolated from soil in Australia (Fig. 1). The G7 (A. deltaense) strains SB2, SB3, and
SB1 also shared the same multilocus haplotype with the strain NCPPB 1641 isolated from the Indian plum (Oemleria cerasiformis) in the United Kingdom. Furthermore, the strains Rew, Rnw, and Rnr designated as G19 shared the same multilocus haplotype with one another (Fig. 1 and Supplementary Fig. S5).

Thirty-three Iranian strains consisted of 15, 17, 20, and 20 sequence types in the sequences of $a t p D, \operatorname{gyr} B$, recA, and $r p o B$ genes, respectively. The strain groups $\mathrm{Ph} 49, \mathrm{Ph} 20, \mathrm{Ap} 42, \mathrm{Ph} 41$, Nec10, and Ph5 (G4); Ro16, Ro17, Ro18, and Ro19 (G7); and R13 and OT33 (G20) as well as Ft3, Ft1, Fte22, FT11, and FT15 (A. larrymoorei) shared the same sequence types in the atpD gene sequences, whereas the strain groups $\mathrm{Ph} 49, \mathrm{Ph} 20, \mathrm{Ap} 42$, Nec10, Ph38, and Ph5 (G4); Ro17, Ro18, and Ro19 (G7); fic9 and Fic72 (G14); and R13 and OT33 (G20) as well as Ft3, Ft1, Fte22, and FT11 (A. larrymoorei) shared the same sequence types in the $g y r B$ gene sequences. The strains $\mathrm{Nec} 10, \mathrm{Ph} 41, \mathrm{Ph} 49, \mathrm{Ph} 20$, and $\mathrm{Ph} 5$ (G4) and fic9 and Fic72 (G14) as well as FT11 and FT15 (A. larrymoorei) shared the same sequence types in the recA gene sequences. In the rpoB gene sequences, the strain groups $\mathrm{Ph} 41$ and Ph5 (G4) and fic9 and Fic72 (G14) as well as FT11 and FT15 (A. larrymoorei) shared the same sequence types.

Because recombination between the housekeeping genes of our MLSA scheme could obscure the real relationships of strains when analyzing the combined phylogeny, we investigated the power of each single gene in discriminating our newly described genomospecies from others. In all four gene phylogenies, G19 and G20 strains unambiguously formed monophyletic groups and grouped separately from other well-defined species. However, in the recA and $g y r B$ trees, the lone Ap1 grouped within the G1 clade. Based on the atpD and $r p o B$ gene sequences, strain Ap1 was grouped with

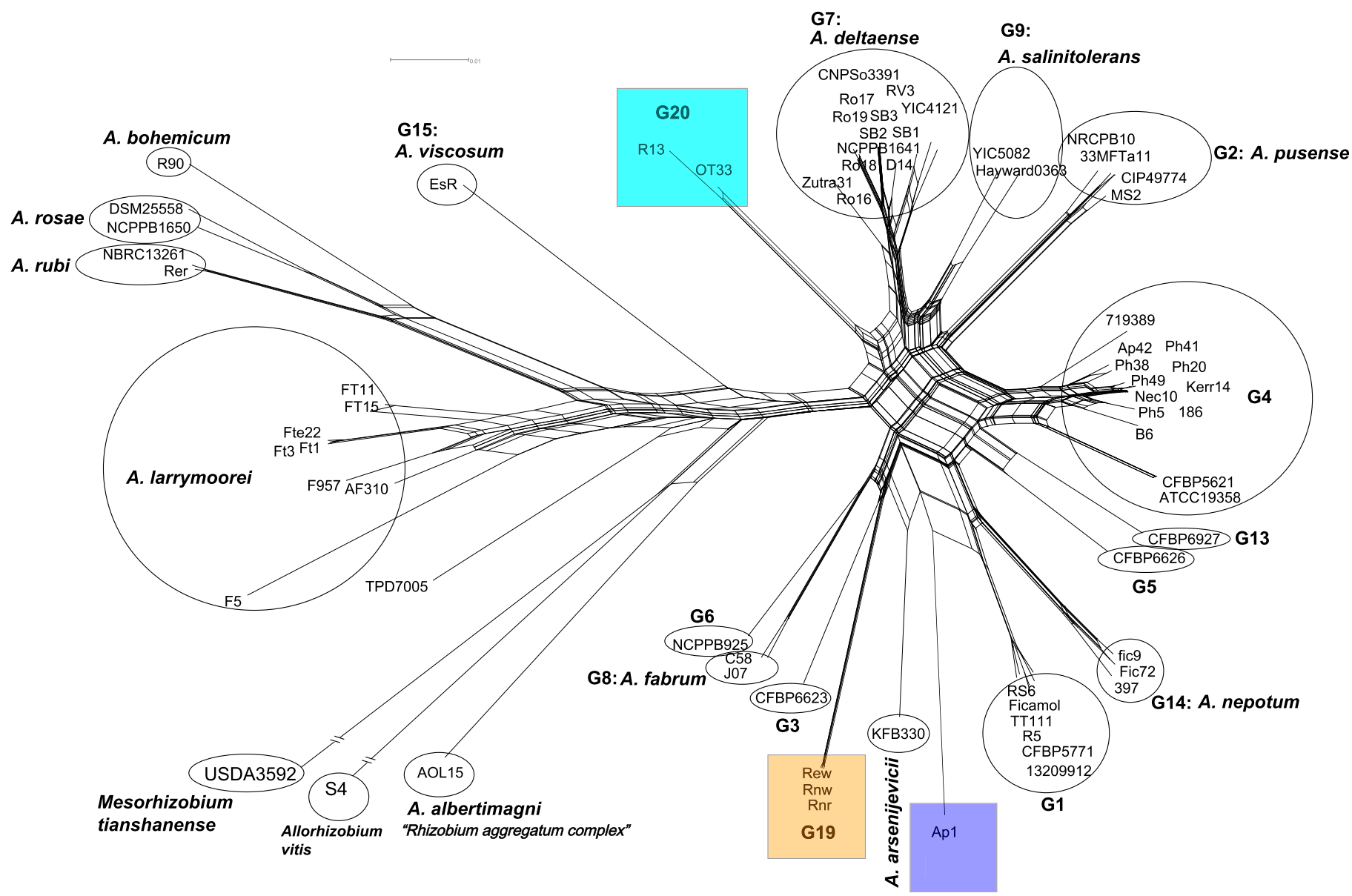

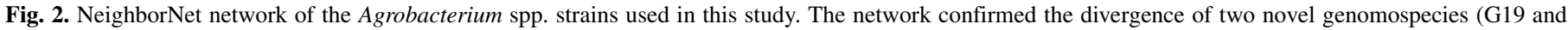
G20) from the previously described taxa within the A. tumefaciens species complex. 
A. albertimagni $\mathrm{AOL} 15^{\mathrm{T}}$ or basal to the A. tumefaciens complex; however, low branch supports indicate that atpD and rpoB phylogenetic placements are not incompatible with each other. This suggests that strain Ap1 might be recombinant: a G1-like genotype received a significant amount of horizontal gene transfer (HGT) from some basal Agrobacterium or Rhizobium lineage. It is impossible to further conclude based on the limited evidence provided by MLSA; additional investigation using whole-genome sequencing and reconstructing the HGT history would help resolve this matter (Lassalle et al. 2017).

The PHI test found statistically significant evidence for recombination $(P=0.003)$ only in the $r p o B$ gene sequences of the strains evaluated in this study. Furthermore, the RDP detected evidence for recombination in the $r p o B$ gene sequences in five of seven nonparametric detection methods. The strain OT33 was identified to be recombined by a DNA fragment sourced from Rnw in the $r p o B$ gene sequences. Nevertheless, no evidence for recombination was found in the $a t p D, g y r B$, and $r e c A$ genes using SplitsTree and RDP software. Hence, a maximum likelihood phylogenetic tree was constructed using the sequences of three recombination-free housekeeping genes (i.e., atpD, gyrB, and recA) to determine whether the phylogenetic position of the six atypical strains was distraught by the recombinant $r p o B$ gene sequences. The three-gene maximum likelihood tree was in congruence with the tree generated by four genes, confirming the divergence of the G19 and G20 strains as novel genomospecies as well as the Ap1 strain as an atypical clade (Supplementary Fig. S6). Furthermore, both the PHI test and RDP did find statistically significant evidence for recombination $\left(P=3.77 \times 10^{-11}\right.$ in the PHI test $)$ in the concatenated sequences of the four genes (Fig. 2).

\section{DISCUSSION}

In this study, through pathogenicity assays and molecularphylogenetic analyses, we determined the taxonomic status of 43 agrobacterial strains isolated from crown gall tissues of annual crops, fruit trees, and ornamental plants in Iran. Although all of the grapevine strains belonged to Allorhizobium vitis, the remaining 33 strains isolated from apple, nectarine, peach, rose, sugar beet, and weeping fig were scattered among various species of Agrobacterium spp. One strain (Rer) was identified as A. rubi, seven strains (i.e., F5, F957, Ft1, FT11, FT15, Ft3, and Fte22) were identified as $A$. larrymoorei, and the remaining 25 strains were assigned to different species/genomospecies of the A. tumefaciens species complex based on the phylogeny of four housekeeping genes (i.e., atpD, gyrB, recA, and $r p o B$ ). Alongside the first report of A. deltaense, A. nepotum, A. rubi, and "A. viscosum" in Iran, based on the results of phylogenetic analyses and genetic diversity statistics, we identified two novel genomospecies (i.e., G19 and G20) within the A. tumefaciens species complex, whereas an atypical apple strain (Ap1) remains taxonomically undetermined.

Ten grapevine strains were identified as Allorhizobium vitis based on the PCR results using the species-specific primer pair PGF/PGR. According to the pathogenicity assays and random amplified polymorphic DNA analyses, Iranian grapevine strains were reported to be homogeneous (Mafakheri 2015). Allorhizobium vitis has previously been reported as the main causal agent of grapevine crown gall in Iran, although $A$. radiobacter has also infrequently been isolated from the same host (Rouhrazi and Rahimian 2012). Similar results were reported for the grapevine strains in other countries (Burr et al. 1998). The remaining 33 strains were scattered within 10 distinct taxa. The strains differed from one another not only in their phylogenetic position but also, in the pathogenicity patterns on tomato, sunflower, and carrot root discs. Although all of the strains identified as G1 (i.e., R5 and Ficamol), A. deltaense (i.e., Ro16, Ro17, Ro18, Ro19, SB1, SB2, and SB3), "A. viscosum" (i.e., EsR), A. rubi (i.e., Rer), and A. larrymoorei (i.e., F5, F957, Ft1, FT11, FT15, Ft3, and Fte22) were pathogenic on all three tested plant species, the strains assigned to the other taxa showed variable pathogenicity on the test plants. For instance, none of the A. nepotum strains (i.e., fic9 and Fic72) were pathogenic on tomato and sunflower, whereas they showed only delayed tumorigenicity on carrot root discs $35 \mathrm{dpi}$, which was considered as nonpathogenicity according to our criteria. Variability was also observed within the Iranian G4 strains, where Ph38 and Ph49, which were isolated from peach in Mazandaran province, were only pathogenic on carrot root discs. Among the two novel genomospecies (i.e., G19 and G20), only the G19 strains were pathogenic on all tested plant species, whereas the G20 strains and atypical Ap1 strain were only pathogenic on carrot root discs.

The number of nucleotide differences in the sequences of four housekeeping genes in the six atypical strains isolated in Iran supports their differentiation from the previously described taxa within the A. tumefaciens species complex (Table 2). For instance, considering the concatenated sequences of the four genes, the number of differences between G19 and its closest neighbor clade G3 was 122 nucleotides (6.0\% difference), which was higher than the differences observed in the G3 vs. G4 ( 82 nucleotides $=4.0 \%$ ), G3 vs. G6 (110 nucleotides $=5.4 \%)$, and G3 vs. G7 $(111$ nucleotides $=$ $5.5 \%$ ) sets of taxa. Interestingly, the phylogenetic distance between

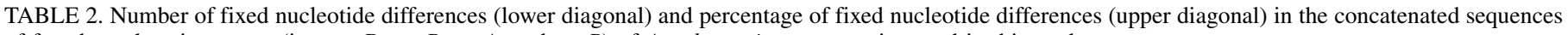
of four housekeeping genes (i.e., atpD, gyrB, recA, and rpoB) of Agrobacterium spp. strains used in this study

\begin{tabular}{|c|c|c|c|c|c|c|c|c|c|c|c|c|c|c|c|c|c|c|c|c|}
\hline Taxon & 1 & 2 & 3 & 4 & 5 & 6 & 7 & 8 & 9 & 10 & 11 & 12 & 13 & 14 & 15 & 16 & 17 & 18 & 19 & 20 \\
\hline G1 & 0 & 7.1 & 5.7 & 3.0 & 5.2 & 6.6 & 5.2 & 6.3 & 6.2 & 6.4 & 3.3 & 9.6 & 6.9 & 7.3 & 5.6 & 6.8 & 12.6 & 11.1 & 12.5 & 4.6 \\
\hline G2 & 144 & 0 & 6.7 & 3.1 & 6.5 & 6.6 & 3.6 & 6.7 & 3.4 & 6.3 & 7.3 & 8.8 & 8.0 & 6.6 & 10.2 & 5.9 & 12.3 & 11.3 & 13.3 & 7.5 \\
\hline G3 & 116 & 136 & 0 & 4.0 & 6.8 & 5.4 & 5.5 & 5.4 & 6.4 & 6.9 & 6.3 & 9.8 & 6.0 & 7.3 & 10.5 & 7.9 & 13.1 & 11.5 & 13.6 & 6.0 \\
\hline G4 & 60 & 63 & 82 & 0 & 3.0 & 3.6 & 2.2 & 3.9 & 2.5 & 3.3 & 3.2 & 8.3 & 5.2 & 4.3 & 7.2 & 5.2 & 10.8 & 9.9 & 11.8 & 3.8 \\
\hline G5 & 105 & 132 & 138 & 60 & 0 & 6.8 & 4.3 & 6.2 & 5.4 & 4.4 & 5.2 & 10.0 & 7.1 & 6.9 & 8.8 & 7.2 & 12.6 & 11.5 & 13.3 & 5.6 \\
\hline G6 & 133 & 133 & 110 & 72 & 137 & 0 & 5.1 & 4.0 & 5.7 & 6.5 & 6.7 & 10.5 & 6.6 & 7.0 & 10.7 & 7.6 & 13.4 & 11.8 & 14.0 & 6.6 \\
\hline G7 & 106 & 73 & 111 & 44 & 87 & 103 & 0 & 4.2 & 1.7 & 3.9 & 5.2 & 7.4 & 6.4 & 3.3 & 7.4 & 4.9 & 9.8 & 9.0 & 10.3 & 6.0 \\
\hline G8 & 128 & 136 & 109 & 79 & 126 & 82 & 85 & 0 & 4.9 & 6.6 & 6.5 & 9.5 & 6.2 & 6.0 & 9.5 & 6.6 & 12.6 & 11.3 & 13.0 & 6.4 \\
\hline G9 & 126 & 68 & 129 & 51 & 109 & 115 & 35 & 100 & 0 & 5.7 & 6.3 & 8.3 & 7.6 & 5.2 & 8.5 & 5.7 & 11.2 & 10.4 & 12.1 & 6.9 \\
\hline G13 & 129 & 127 & 140 & 66 & 90 & 132 & 79 & 134 & 116 & 0 & 6.1 & 10.2 & 7.5 & 6.8 & 9.8 & 7.9 & 12.7 & 11.9 & 13.5 & 7.3 \\
\hline G14 & 66 & 148 & 127 & 64 & 106 & 136 & 105 & 132 & 128 & 124 & 0 & 9.9 & 7.4 & 7.6 & 7.5 & 7.1 & 12.7 & 11.6 & 13.0 & 4.8 \\
\hline G15 & 194 & 179 & 199 & 168 & 202 & 213 & 150 & 193 & 168 & 207 & 200 & 0 & 10.8 & 9.3 & 11.0 & 6.5 & 11.0 & 10.0 & 12.5 & 10.7 \\
\hline G19 & 140 & 163 & 122 & 106 & 143 & 134 & 129 & 125 & 154 & 153 & 150 & 218 & 0 & 8.4 & 10.8 & 8.1 & 13.5 & 12.3 & 14.0 & 6.7 \\
\hline G20 & 148 & 133 & 148 & 88 & 140 & 141 & 67 & 122 & 105 & 138 & 154 & 189 & 171 & 0 & 10.0 & 6.9 & 11.7 & 11.1 & 12.9 & 7.8 \\
\hline Ap1 & 114 & 207 & 212 & 145 & 178 & 216 & 150 & 192 & 172 & 199 & 153 & 223 & 219 & 202 & 0 & 6.2 & 12.4 & 11.2 & 12.8 & 9.4 \\
\hline A. larrymoorei & 138 & 119 & 160 & 106 & 145 & 154 & 100 & 134 & 115 & 160 & 144 & 131 & 165 & 140 & 125 & 0 & 5.2 & 4.9 & 7.2 & 7.7 \\
\hline A. rubi & 255 & 249 & 265 & 218 & 256 & 272 & 198 & 256 & 228 & 257 & 257 & 223 & 274 & 238 & 251 & 105 & 0 & 4.1 & 6.4 & 13.1 \\
\hline A. rosae & 226 & 229 & 234 & 200 & 234 & 239 & 183 & 230 & 210 & 242 & 235 & 203 & 249 & 224 & 228 & 99 & 84 & 0 & 4.6 & 12.0 \\
\hline A. bohemicum & 254 & 269 & 276 & 239 & 270 & 284 & 209 & 264 & 245 & 273 & 263 & 254 & 284 & 261 & 260 & 146 & 130 & 93 & 0 & 13.7 \\
\hline A. arsenijevicii & 93 & 153 & 122 & 78 & 114 & 134 & 122 & 130 & 140 & 147 & 98 & 217 & 135 & 158 & 190 & 156 & 265 & 243 & 278 & 0 \\
\hline
\end{tabular}


G3 and A. arsenijevicii was similar to the distance observed between G3 and G19 (122 nucleotides $=6.0 \%$ ) (Table 2). Furthermore, the fixed difference between G20 (i.e., R13 and OT33) and its closest neighbor clade A. deltaense was 67 nucleotides (3.3\%). A. deltaense (G7) is a phylogenetically diverse taxon that includes both pathogenic and nonpathogenic agrobacteria, whereas the G20 strains are phylogenetically closer to the nonpathogenic counterparts of the species (Bouri et al. 2016; Mougel et al. 2002; Yan et al. 2017a). The apple strain Ap1 also differed from the G1 strains by 114 nucleotides (5.6\%), whereas assessment of the nucleotide distances in the sequences of individual genes did not support delineation of the strain into a distinct clade. Instead, recombination analyses propose that the strain Ap1-phylogenetically closely related to the G1 genomospecies-is most likely a recombinant clade with an unknown parental taxon. The phylogenetic distance between the two genomospecies described in this study and their neighbor clades was higher than the differences between some previously defined genomospecies. For instance, there were only 82 nucleotide differences (4.0\%) between G6 and G8 ("A. fabrum") in the concatenated sequences (Table 2). All of this evidence supports the hypothesis that the two atypical phylogroups within the A. tumefaciens species complex could be considered as two novel genomospecies (i.e., G19 and G20). Nevertheless, additional complete genome sequence-based studies are warranted to decipher if the novel taxa represent formal bona fide species (de Lajudie et al. 2019). However, phylogeny of the $a t p D$, $r e c A$, and $r p o B$ gene sequences revealed that strain EsR isolated from rose in Isfahan in 2018 was identified as " $A$. viscosum" (G15), although a formal bona fide taxonomic description for the species has yet to be published (Kuzmanović et al. 2018a; Ramírez-Bahena et al. 2014).

A. nepotum strains were isolated from grapevine, raspberry, and stone fruits, and they were mostly reported to be nonpathogenic on the tested plant species (Mousavi et al. 2015; Puławska et al. 2012). In this study, the strains Fic72 and fic9 isolated from weeping fig were identified as A. nepotum, and they were nonpathogenic on all of the tested plant species. The expected DNA fragment was amplified using all of the tumour inducing plasmid-specific primer pairs in both the Fic 72 and fic 9 strains, indicating that they still carry the Ti plasmid. Additional investigations are needed to explain the contradictory results observed on different experiments. For instance, sequencing of the Ti plasmid could reveal whether the vir region is attenuated in the plasmid of these strains. However, although the strains Fte1 and Fte 3 were pathogenic on all of the tested plants, no DNA amplification was observed in the PCRs using VCF/VCR and virD2A/virD2C primer pairs, which were designed to amplify 730- and 224-base pair DNA fragments in the virC and virD genes, respectively (Haas et al. 1995; Sawada et al. 1995). False-negative results using the VCF/VCR primer pair were previously reported (Yakabe et al. 2012). Similar conflicting results were also observed in strains R13 and OT33 (Table 1). The primer pair tms2F1/tms2R2 led to the amplification of the expected fragment in these strains, whereas the other pTi-specific primer pairs resulted in a variable pattern (Table 1). For instance, the 224base pair expected DNA fragment was not amplified using the virD2A/virD2C primer pair in strains R13 and OT33, whereas the VCF/VCR primer pair directed the amplification of a 730-base pair DNA fragment of virC in strain R13 but not in OT33. It could be hypothesized that the primer pairs introduced for the specific detection of crown gall-inducing agrobacteria are neither sufficiently specific nor sensitive.

In conclusion, the results of this study provide novel insight into the diversity and taxonomic position of Agrobacterium spp. strains associated with annual crops, fruit trees, and ornamental plants. Our phylogenetic analyses revealed that two novel genomospecies possessing different patterns of pathogenicity features could be defined within the A. tumefaciens species complex. This highlights, on one hand, the wider genetic diversity of the crown gall pathogen(s) than has previously been described and underlines at the same time the potential threats owing to crown gall outbreaks by the newly emerging species. On the other hand, the occurrence of a recombinant strain with unclear species affiliation (Ap1) as well as the limited efficiency of regular PCR detection of Ti plasmids on strains that are pathogenic emphasize the need to develop new and state-of-the-art detection techniques to prevent the spread of highly virulent strains via infected plantlets and saplings. Notably, whole-genome sequencing comes at a growingly cheaper cost and provides all of the possible information for taxonomic assignation and prediction of virulence potential; it is thus the evident tool of tomorrow's epidemiology (Davis et al. 2016). Considering a number of economically important crown gall outbreaks in sugar beet fields and ornamental plant nurseries in Iran (Mafakheri et al. 2017) and taking to the account the potential threats of crown gall epidemics around the globe (Nyvall 1979), more strict inspections and surveys are recommended to limit the risk of crop losses because of the crown gall pathogen infection.

\section{LITERATURE CITED}

Amani, B. 1966. Stem and root gall of grapevine. Iranian J. Plant Pathol. 3: 12-18.

Ansari, M., Taghavi, S. M., Zarei, S., Mehrb-Moghadam, S., Mafakheri, H., Hamidizade, M., and Osdaghi, E. 2019. Phenotypically and genotypically heterogeneous strains of Pseudomonas syringae associated with alfalfa leaf spot disease in Iran. Plant Dis. doi.org/10.1094/PDIS-06-19-1153-RE

Bosmans, L., Alvarez-Perez, S., Moerkens, R., Wittemans, L., Van Calenberge, B., Van Kerckhove, S., Paeleman, A., De Mot, R., Rediers, H., and Lievens, B. 2015. Assessment of the genetic and phenotypic diversity among rhizogenic Agrobacterium biovar 1 strains infecting solanaceous and cucurbit crops. FEMS Microbiol. Ecol. 91:fiv081.

Bouri, M., Chattaoui, M., Gharsa, H. B., McClean, A., Kluepfel, D., Nesme, X., and Rhouma, A. 2016. Analysis of Agrobacterium populations isolated from tunisian soils: Genetic structure, avirulent-virulent ratios and characterization of tumorigenic strains. J. Plant Pathol. 98:265-274.

Bouzar, H., and Jones, J. B. 2001. Agrobacterium larrymoorei sp. nov., a pathogen isolated from aerial tumors of Ficus benjamina. Int. J. Syst. Evol. Microbiol. 51:1023-1026.

Burr, T. J., Bazzi, C., Süle, S., and Otten, L. 1998. Crown gall of grape: Biology of Agrobacterium vitis and the development of disease control strategies. Plant Dis. 82:1288-1297.

Campillo, T., Lavire, C., Shams, M., Pothier, J. F., and Puławska, J. 2012. Detection and identification methods and new tests as developed and used in the framework of Cost873 for bacteria pathogenic to stone fruits and nuts. J. Plant Pathol. 94:97-104.

Clement, M., Snell, Q., Walker, P., Posada, D., and Crandall, K. 2002. TCS: Estimating gene genealogies. Page 184 in: Proceedings of the 16th International Parallel and Distributed Processing Symposium. IEEE, Los Alamitos, CA. doi.org/10.1109/IPDPS.2002.1016585

Costechareyre, D., Rhouma, A., Lavire, C., Portier, P., Chapulliot, D., Bertolla, F., Boubaker, A., Dessaux, Y., and Nesme, X. 2010. Rapid and efficient identification of Agrobacterium species by recA allele analysis: Agrobacterium recA diversity. Microb. Ecol. 60:862-872.

Davis, E. W., II, Weisberg, A. J., Tabima, J. F., Grunwald, N. J., and Chang, J. H. 2016. Gall-ID: Tools for genotyping gall-causing phytopathogenic bacteria. PeerJ 4:e2222.

de Lajudie, P. M., Andrews, M., Ardley, J., Eardly, B., Jumas-Bilak, E., Kuzmanović, N., Lassalle, F., Lindström, K., Mhamdi, R., Martínez-Romero, E., Moulin, L., Mousavi, S. A., Nesme, X., Peix, A., Puławska, J., Steenkamp, E., Stępkowski, T., Tian, C.-F., Vinuesa, P., Wei, G., Willems, A., Zilli, J., and Young, P. 2019. Minimal standards for the description of new genera and species of rhizobia and agrobacteria. Int. J. Syst. Evol. Microbiol. 69:1852-1863.

De Ley, J., Tijtgat, R., De Smedt, J., and Michiels, M. 1973. Thermal stability of DNA - DNA hybrids within genus Agrobacterium. J. Gen. Microbiol. 78: 241-252.

Farrand, S. K., Van Berkum, P. B., and Oger, P. 2003. Agrobacterium is a definable genus of the family Rhizobiaceae. Int. J. Syst. Evol. Microbiol. 53:1681-1687.

Haas, J. H., Moore, L. W., Ream, W., and Manulis, S. 1995. Universal PCR primers for detection of phytopathogenic Agrobacterium strains. Appl. Environ. Microbiol. 61:2879-2884. 
Holmes, B., and Roberts, P. 1981. The classification, identification and nomenclature of agrobacteria. J. Appl. Bacteriol. 50:443-467.

Huson, D. H., and Bryant, D. 2006. Application of phylogenetic networks in evolutionary studies. Mol. Biol. Evol. 23:254-267.

Jarvis, B. D. W., Sivakumaran, S., Tighe, S. W., and Gillis, M. 1996. Identification of Agrobacterium and Rizobium species based on cellular fatty acid composition. Plant Soil 184:143-158.

Keane, P. J., Kerr, A., and New, P. B. 1970. Crown gall of stone fruit II. Identification and nomenclature of agrobacterium isolates. Aust. J. Biol. Sci. 23:585-595

Kerr, A., and Panagopoulos, C. G. 1977. Biotypes of Agrobacterium radiobacter var. tumefaciens and their biological control. Phytopathol. Z. 90: 172-179.

Kersters, K., De Ley, J., Sneath, P. H. A., and Sackin, M. 1973. Numerical taxonomic analysis of Agrobacterium. J. Gen. Microbiol. 78:227-239.

Kuzmanović, N., Puławska, J., Prokić, A., Ivanović, M., Zlatković, N., Jones, J. B., and Obradović, A. 2015. Agrobacterium arsenijevicii sp. nov., isolated from crown gall tumors on raspberry and cherry plum. Syst. Appl. Microbiol. 38:373-378.

Kuzmanović, N., Puławska, J., Smalla, K., and Nesme, X. 2018a. Agrobacterium rosae sp. nov., isolated from galls on different agricultural crops. Syst. Appl. Microbiol. 41:191-197.

Kuzmanović, N., Smalla, K., Gronow, S., and Puławska, J. 2018b. Rhizobium tumorigenes sp. nov., a novel plant tumorigenic bacterium isolated from cane gall tumors on thornless blackberry. Sci. Rep. 8:9051.

Lassalle, F., Campillo, T., Vial, L., Baude, J., Costechareyre, D., Chapulliot, D., Sham, M., Abrouk, D., Lavire, C., Oger-Desfeux, C., Hommais, F., Guéguen, L., Daubin, V., Muller, D., and Nesme, X. 2011. Genomic species are ecological species as revealed by comparative genomics in Agrobacterium tumefaciens. Genome Biol. Evol. 3:762-781.

Lassalle, F., Planel, R., Penel, S., Chapulliot, D., Barbe, V., Dubost, A., Calteau, A., Vallenet, D., Mornico, D., Bigot, T., Guéguen, L., Vial, L., Muller, D., Daubin, V., and Nesme, X. 2017. Ancestral genome estimation reveals the history of ecological diversification in Agrobacterium. Genome Biol. Evol. 9:3413-3431.

Leigh, J. W., and Bryant, D. 2015. popart: Full-feature software for haplotype network construction. Methods Ecol. Evol. 6:1110-1116.

Librado, P., and Rozas, J. 2009. DnaSP v5: A software for comprehensive analysis of DNA polymorphism data. Bioinformatics 25:1451-1452.

Lindstrom, K., and Young, J. W. 2011. International committee on systematics of prokaryotes subcommittee on the taxonomy of Agrobacterium and Rhizobium: Minutes of the meeting. Int. J. Syst. Evol. Microbiol. 61: 3089-3093.

Mafakheri, H. 2015. Genotypic characteristics of Agrobacterium isolates from different hosts in western and southern provinces of Iran. Master's thesis. Shiraz University, Shiraz, Iran.

Mafakheri, H., Taghavi, S. M., Banihashemi, Z., Osdaghi, E., and Lamichhane, J. R. 2017. Pathogenicity, host range and phylogenetic position of Agrobacterium species associated with sugar beet crown gall outbreaks in Southern Iran. Eur. J. Plant Pathol. 147:721-730.

Martin, D. P., Murrell, B., Golden, M., Khoosal, A., and Muhire, B. 2015. RDP4: Detection and analysis of recombination patterns in virus genomes. Virus Evol. 1:vev003.

Moore, L. W., Bouzar, H., and Burr, T. J. 2001. Gram-negative bacteria: Agrobacterium. Pages 17-35 in: Laboratory Guide for Identification of Plant Pathogenic Bacteria, N. W. Schaad, J. B. Jones, and W. Chun, eds. APS Press, St. Paul, MN.

Mougel, C., Thioulouse, J., Perriere, G., and Nesme, X. 2002. A mathematical method for determining genome divergence and species delineation using AFLP. Int. J. Syst. Evol. Microbiol. 52:573-586.

Mousavi, S. A., Willems, A., Nesme, X., de Lajudie, P., and Lindström, K. 2015. Revised phylogeny of Rhizobiaceae: Proposal of the delineation of Pararhizobium gen. nov., and 13 new species combinations. Syst. Appl. Microbiol. 38:84-90.

Nyvall, R. F. 1979. Field Crop Diseases Handbook. Avi Publishing Company, Inc., Westport, CT.

Ophel, K., and Kerr, A. 1990. Agrobacterium vitis sp. nov. for strains of Agrobacterium biovar 3 from grapevines. Int. J. Syst. Evol. Microbiol. 40: 236-241.

Ormeño-Orrillo, E., Servín-Garcidueñas, L. E., Rogel, M. A., González, V., Peralta, H., Mora, J., Martínez-Romero, J., and Martínez-Romero, E. 2015. Taxonomy of rhizobia and agrobacteria from the Rhizobiaceae family in light of genomics. Syst. Appl. Microbiol. 38:287-291.

Osdaghi, E., Ansari, M., Taghavi, S. M., Zarei, S., Koebnik, R., and Lamichhane, J. R. 2018a. Pathogenicity and phylogenetic analysis of Clavibacter michiganensis strains associated with tomato plants in Iran. Plant Pathol. 67:957-970.

Osdaghi, E., Taghavi, S. M., Calamai, S., Biancalani, C., Cerboneschi, M., Tegli, S., and Harveson, R. M. 2018b. Phenotypic and molecular- phylogenetic analysis provide novel insights into the diversity of Curtobacterium flaccumfaciens. Phytopathology 108:1154-1164.

Osdaghi, E., Taghavi, S. M., Fazliarab, A., Elahifard, E., and Lamichhane, J. R. 2015. Characterization, geographic distribution and host range of Curtobacterium flaccumfaciens: An emerging bacterial pathogen in Iran. Crop Prot. 78:185-192.

Osdaghi, E., Taghavi, S. M., Hamzehzarghani, H., Fazliarab, A., Harveson, R. M., and Lamichhane, J. R. 2016. Occurrence and characterization of a new red-pigmented variant of Curtobacterium flaccumfaciens, the causal agent of bacterial wilt of edible dry beans in Iran. Eur. J. Plant Pathol. 146: 129-145.

Panday, D., Schumann, P., and Das, S. K. 2011. Rhizobium pusense sp. nov., isolated from the rhizosphere of chickpea (Cicer arietinum L.). Int. J. Syst. Evol. Microbiol. 61:2632-2639.

Portier, P., Fischer-Le Saux, M., Mougel, C., Lerondelle, C., Chapulliot, D., Thioulouse, J., and Nesme, X. 2006. Identification of genomic species in Agrobacterium biovar 1 by AFLP genomic markers. Appl. Environ. Microbiol. 72:7123-7131.

Puławska, J. 2010. Crown gall of stone fruits and nuts, economic significance and diversity of its causal agents: Tumorigenic agrobacterium spp. J. Plant Pathol. 92:87-98.

Puławska, J. 2016. Crown gall on stone fruit trees. Acta Hortic. 1149:37-42.

Puławska, J., and Kałużna, M. 2011. Phylogenetic relationship and genetic diversity of Agrobacterium spp. isolated in Poland based on gyrB gene sequence analysis and RAPD. Eur. J. Plant Pathol. 133:379-390.

Puławska, J., Maes, M., Willems, A., and Sobiczewski, P. 2000. Phylogenetic analysis of 23S rRNA gene sequences of. Agrobacterium, Rhizobium and Sinorhizobium strains. Syst. Appl. Microbiol. 23:238-244.

Puławska, J., and Sobiczewski, P. 2005. Development of a semi-nested PCR based method for sensitive detection of tumorigenic Agrobacterium in soil. J. Appl. Microbiol. 98:710-721.

Puławska, J., Warabieda, W., and Ismaila, E. 2016. Identification and characterization of bacteria isolated from crown galls on stone fruits in Poland. Plant Pathol. 65:1034-1043.

Puławska, J., Willems, A., De Meyer, S. E., and Sulec, S. 2012. Rhizobium nepotum sp. nov. isolated from tumors on different plant species. Syst. Appl. Microbiol. 35:215-220.

Ramírez-Bahena, M. H., Vial, L., Lassalle, F., Diel, B., Chapulliot, D., Daubin, V., Nesme, X., and Muller, D. 2014. Single acquisition of protelomerase gave rise to the speciation of a large and diverse clade within the Agrobacterium/Rhizobium supercluster characterized by the presence of a linear chromid. Mol. Phylogenet. Evol. 73:202-207.

Rouhrazi, K., and Rahimian, H. 2012. Characterization of Iranian grapevine isolates of Rhizobium (Agrobacterium) spp. J. Plant Pathol. 94:555-560.

Sawada, H., Ieki, H., and Matsuda, I. 1995. PCR detection of Ti and Ri plasmids from phytopathogenic Agrobacterium strains. Appl. Environ. Microbiol. 61:828-831.

Sawada, H., Ieki, H., Oyaizu, H., and Matsumoto, S. 1993. Proposal for rejection of Agrobacterium tumefaciens and revised descriptions for the genus Agrobacterium and for Agrobacterium radiobacter and Agrobacterium rhizogenes. Int. J. Syst. Bacteriol. 43:694-702.

Sedighian, N., Shams-Bakhsh, M., Osdaghi, E., and Khodaygan, P. 2014. Etiology and host range of bacterial leaf blight and necrosis of squash and muskmelon in Iran. J. Plant Pathol. 96:507-514.

Shams, M., Vial, L., Chapulliot, D., Nesme, X., and Lavire, C. 2013. Rapid and accurate species and genomic species identification and exhaustive population diversity assessment of Agrobacterium spp. using recA-based PCR. Syst. Appl. Microbiol. 36:351-358.

Szegedi, E., and Bottka, S. 2002. Detection of Agrobacterium vitis by polymerase chain reaction in grapevine bleeding sap after isolation on a semiselective medium. Vitis 41:37-42.

Tamura, K., Stecher, G., Peterson, D., Filipski, A., and Kumar, S. 2013. MEGA6: Molecular evolutionary genetics analysis version 6.0. Mol. Biol. Evol. 30:2725-2729.

Tighe, S. W., de Lajudie, P., Dipietro, K., Lindström, K., Nick, G., and Jarvis, B. D. 2000. Analysis of cellular fatty acids and phenotypic relationships of Agrobacterium, Bradyrhizobium, Mesorhizobium, Rhizobium and Sinorhizobium species using the Sherlock Microbial Identification System. Int. J. Syst. Evol. Microbiol. 50:787-801.

Tzfira, T., and Citovsky, V., eds. 2008. Agrobacterium: From Biology to Biotechnology. Springer Science \& Business Media, New York, NY.

White, L. O. 1972. The taxonomy of crown-gall organism Agrobacterium tumefaciens and its relationships to rhizobia and other agrobacteria. J. Gen. Microbiol. 72:565-574

Yakabe, L. E., Maccree, M. M., Sudarshana, P., McClean, A. E., Parker, S. R., Wechter, W. P., Presting, G., Marutani-Hert, M., and Kluepfel, D. A. 2012. Novel PCR primers for detection of genetically diverse virulent Agrobacterium tumefaciens biovar 1 strains. J. Gen. Plant Pathol. 78:121-126. 
Yan, J., Li, Y., Han, X. Z., Che, W. F., Zou, W. X., Xie, Z., and Li, M. 2017a. Agrobacterium deltaense sp. nov., an endophytic bacteria isolated from nodule of Sesbania cannabina. Arch. Microbiol. 199:1003-1009.

Yan, J., Li, Y., Yan, H., Chen, W. F., Zhang, X., Wang, E. T., Han, X. Z., and Xie, Z. H. 2017b. Agrobacterium salinitolerans sp. nov., a saline-alkalinetolerant bacterium isolated from root nodule of Sesbania cannabina. Int. J. Syst. Evol. Microbiol. 67:1906-1911.

Yaripour, Z., Taghavi, S. M., Osdaghi, E., and Lamichhane, J. R. 2018. Host range and phylogenetic analysis of Xanthomonas alfalfae causing bacterial leaf spot of alfalfa in Iran. Eur. J. Plant Pathol. 150:267-274.
Young, J. M., Kuykendall, L. D., Martínez-Romero, E., Kerr, A., and Sawada, H. 2001. as new combinations: Rhizobium radiobacter, $R$. rhizogenes, $R$. rubi, $R$. undicola and $R$. vitis. Int. J. Syst. Evol. Microbiol. 51:89-103.

Zahradník, J., Nunvar, J., Pařízková, H., Kolářová, L., Palyzová, A., Marešová, H., Grulich, M., Kyslíková, E., and Kyslík, P. 2018. Agrobacterium bohemicum sp. nov. isolated from poppy seed wastes in central Bohemia. Syst. Appl. Microbiol. 41:184-190.

Zarei, S., Taghavi, S. M., Banihashemi, Z., Hamzehzarghani, H., and Osdaghi, E. 2019. Etiology of leaf spot and fruit canker symptoms on stone fruits and nut trees in Iran. J. Plant Pathol. doi.org/10.1007/s42161-019-00283-w 